\title{
Avaliação teórico-experimental da deformação por fluência de concretos auto-adensáveis
}

\author{
A. L. N. Ferraz ${ }^{1}$, M. P. Barbosa ${ }^{2}$, F. M. Salles ${ }^{3}$, N. O. Pinto Jr. ${ }^{4}$ \\ ${ }^{1}$ Universidade do Estado de Mato Grosso (Unemat), Brasil. \\ ${ }^{2}$ Universidade Estadual Paulista (Unesp), Brasil. \\ ${ }^{3}$ Laboratorio Cesp de engenharia Civil (Cesp), Brasil. \\ ${ }^{4}$ Universidade Estadual de Campinas (Unicamp), Brasil.
}

\section{Información del artículo DOI: \\ http://dx.doi.org/10.21041/ra.v1 $\underline{i 3.19}$ \\ Artículo recibido el 21 de Julio de 2011, revisado bajo las políticas de publicación de la Revista ALCONPAT y aceptado el 15 de Septiembre de 2011. Cualquier discusión, incluyendo la réplica de los autores se publicará en el segundo número del 2012 siempre y cuando la información se reciba antes del cierre del primero de 2012.}

(C) 2011 Alconpat Internacional

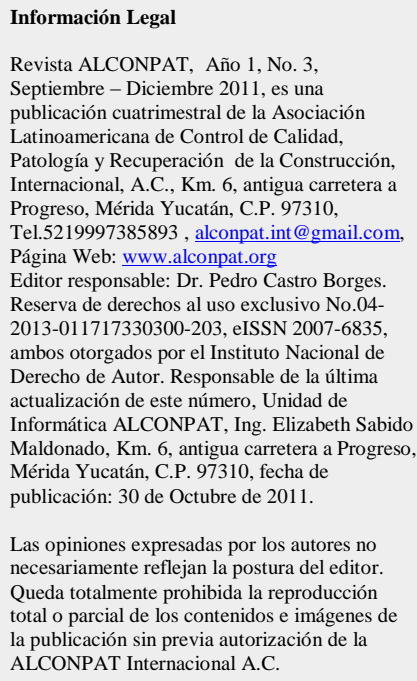

\section{RESUMO}

O comportamento de concretos auto-adensáveis de classes de resistências diferentes - 35 e 55 MPa - são avaliados em relação à deformação sob carregamento lento, fluência básica, nas idades de 7, 14, 28 e 56 dias, e em relação as deformações devidas a retração por secagem. Ensaios de resistência à compressão, resistência à tração, e módulo de elasticidade foram executados para a caracterização mecânica complementar dos compósitos. Os ensaios de retração se mostraram adequados, apresentando curvas semelhantes com valores de deformação ligeiramente inferiores para os traços com água/cimento igual a 0,45 (concreto "B"). As deformações sob carga (fluência) foram maiores nos concretos com maior relação água/cimento, e menor módulo de elasticidade (concreto "A"). Os corpos-de-prova de idades mais avançadas apresentaram valores menores de fluência. As curvas de fluência apresentaram melhor estabilização nos corpos-de-prova de 28 e 56 dias. Os valores dos coeficientes calculados pela NBR 6118 (ABNT, 2003) apresentaram boa correlação com os coeficientes calculados experimentalmente.

Palavras-chave: fluência; retração; deformações em concretos; concreto auto-adensável.

\section{ABSTRACT}

The performance of self-compacting concretes of different classes - 35 e $55 \mathrm{MPa}$ - were evaluated in relation to deformation under slow loading, basic creep, at ages of 7, 14, 28 and 56 days, and in relation to deformation due to shrinkage by drying. Test of compressive strength, tensile strength and elastic modulus were performed on the composites. The shrinkage results were appropriate, presenting similar curves with deformation values slightly lower for mixtures of water/cement equal to 0,45 (concrete "B"). The deformations under load (creep) were higher in the concretes with higher water/cement ratios and lower elastic moduli (concrete "A"). The more aged elements showed lower values of creep; the creep curves showed better stability in the elements with 28 and 56 days. The values of coefficients calculated as per NBR 6118 (ABNT, 2003) showed good correlation with the coefficients calculated experimentally.

Keywords: creep; shrinkage; deformations in concretes; self-compacting concrete.

Autor de contacto: M. P. Barbosa (mbarbosa@dec.feis.unesp.br) 
Revista ALCONPAT, Volumen 1, Número 3, Septiembre-Diciembre 2011, Páginas 233 - 249

\section{INTRODUÇÃO}

O emprego do Concreto Auto-Adensável (CAA), seja na indústria de pré-fabricados, seja em canteiros de obra, é uma realidade dos dias de hoje na Europa, Japão, Estados Unidos e, vem crescendo cada vez mais nos países da America do Sul. A necessidade de avaliar seu comportamento reológico e mecânico, sobretudo em relação à fissuração devido à retraçao e à fluência do material, motivou a realização deste estudo.

Uma das caractéristicas do CAA, que lhe permite ser lançado facilmente sem necessidade de vibração ou outros meios de compactação, mantendo-se homogêneo, coeso e sem segregação ( $\mathrm{Su}$ et al., 2001; Okamura, 1997), é a alta fluidez que este material oferece. Embora existam modificações nas proporções das misturas, faz-se necessário a utilização de aditivos superplastificantes na sua produção, assim como um aumento na proporçao de materiais finos. De acordo com Su et al. (2001), uma dosagem adequada de superplastificante tende a aumentar a fluidez, a habilidade de autocompactar-se e a resistência à segregação do concreto no estado fresco.

Nos projetos de estruturas de concreto, o conhecimento das propriedades dos materiais é primordial para sua perfeita segurança, sendo que, o valor da fluência e da retração são parâmetros importantes em diversos casos. Embora seja possível encontrar na literatura internacional trabalhos sobre as deformações lentas e fissuração do concreto de autodesempenho, no Brasil são poucos os dados disponíveis sobre esse assunto.

A qualidade geral do concreto e a influência do processo de hidratação, dependente do tempo, são funções importantes da deformação do concreto primariamente. Fatores adicionais tais como condições do ambiente, tamanho e forma do elemento, histórico de tensões, mistura do concreto, etc., também afetam o comportamento deformacional das estruturas de concreto.

No concreto as deformações podem ser viscoelásticas parcialmente reversíveis, consistindo de uma fase viscosa e de outra elástica e plástica não reversível (Neville, 1997). Além das deformações próprias causadas pela perda de água (retração) e pela variação de temperatura, existem também as deformações por cargas aplicadas. As deformações elásticas iniciais são seguidas das deformações viscoelásticas do concreto, denominada fluência. A fluência é o aumento da deformação ao longo do tempo, com tensão constante (deformação/carga). A fluencia basica é a deformação sob carga quando o corpo-de-prova encontra-se selado, ou seja, quando este não perde umidade para o meio externo, sendo o processo de hidratação responsável pela redução da umidade no interior do elemento. Outra propriedade que não pode ser desprezada do concreto é a retração. A retração do concreto é a diminuição de volume devido à evaporação do excesso de água que não é consumida no processo de hidratação do cimento, sendo uma deformação que independe do carregamento. Ela é normalmente dividida em dois tipos, "a retração por secagem" e "retração autógena".

A "retração por secagem" é a variação de volume observada no concreto quando este é submetido à variação de umidade, mantida a temperatura, sem nenhuma espécie de carregamento. A“Retração autógena" é definida como a mudança de volume sob temperatura constante, e sem perda de umidade da mistura cimentícia para o meio ambiente, causada pela redução da umidade relativa no interior dos poros em decorrência da evolução da hidratação do cimento.

Segundo Persson (2005), os coeficientes de fluência e retração do CAA são iguais aos do concreto convencional, o que pode ser justificado pelos fatores que afetam as deformações como idade, tipo e quantidade de agregado, ambiente, maturidade, umidade, porosidade, entre outros. Por outro lado, Seng e Shima (2005), avaliaram a fluência e retração em CAA com diferentes quantidades de fíler calcáreo, e concluíram que, a composição de concreto auto-adensável que utilizou maior quantidade de fíler calcáreo apresentou maior fluência; sendo os coeficientes de 
Revista ALCONPAT, Volumen 1, Número 3, Septiembre-Diciembre 2011, Páginas 233 - 249

fluência proporcionais à quantidade de fíler utilizado. Os autores também observaram que a fluência do CAA é maior que a do concreto convencional, mesmo no concreto convencional que contém o mesmo volume de fíler, diferindo de outros autores.

Existe, pois, uma certa divergência em relação aos coeficientes de fluência no CAA. Entretanto, no dimensionamento de estruturas de concreto, é fundamental conhecer seu comportamento quanto às deformações lentas. Nas normas internacionais (American Concrete Institute-ACI 31805), e Brasileiras (NBR 6118, 2003) estão incluídos como parâmetros de cálculo, as deformações do concreto. Com relação à deformação lenta, conhecer o coeficiente de fluência é importante para que o projetista possa prever perdas de tensão em peças protendidas, prever as deformações no caso de descimbramento (Kalintzis, 2000). Portanto, conhecer o comportamento do concreto auto-adensável frente à fluência é um dos requisitos para que se possa, nas Normas Brasileiras de dimensionamento de estruturas de concreto armado e protendido, fornecer parâmetros condizentes com o comportamento desse material.

De acordo com o CEB-FIP (1990), o coeficiente de fluência de um concreto de elevado desempenho $\left(f_{c k}=80 \mathrm{MPa}\right)$ é cerca de $25 \%$ menor do que o de um concreto de resistência normal. No Brasil não há registro de dados a esse respeito. A revisão da norma brasileira NBR 6118 (ABNT, 2003) praticamente mantém as recomendações já existentes anteriormente, e atende a concretos com $f_{c k}$ até $50 \mathrm{MPa}$, apenas. Neste trabalho procurou-se, inicialmente, avaliar as deformações, a retração e a fluência básica, de concretos auto-adensáveis de diferentes classes de resistência, posteriormente objetivou-se calcular os coeficientes experimentais comparando estes valores com os coeficientes calculados pela NBR 6118.

\section{MATERIAIS E PROGRAMA EXPERIMENTAL}

Dois tipos de concreto foram avaliados: um concreto com teor de argamassa de $71 \%$ em volume, relação água/cimento de 0,45 , relação água/finos de 0,36 , apresentando resistência à compressão aos 28 dias de $55 \mathrm{MPa}$, e um concreto com teor de argamassa de $72 \%$ em volume, relação água/cimentos 0,64, relação água/finos igual a 0,41, e resistência à compressão de $35 \mathrm{MPa}$ aos 28 dias.

\subsection{Materiais}

O cimento utilizado foi um cimento de alta resistência inicial, CPV - ARI Plus, cujas características físicas e químicas estão apresentadas na tabela 2. O filer utilizado é de origem basáltica com massa específica de $2,86 \mathrm{~g} / \mathrm{cm}^{3}$, e $39,9 \%$ de material retido na peneira de 0,075 $\mathrm{mm}$ de diâmetro, cujo ensaio de granulometria a laser encontra-se apresentado na Figura 1. $\mu$ 
Revista ALCONPAT, Volumen 1, Número 3, Septiembre-Diciembre 2011, Páginas 233 - 249

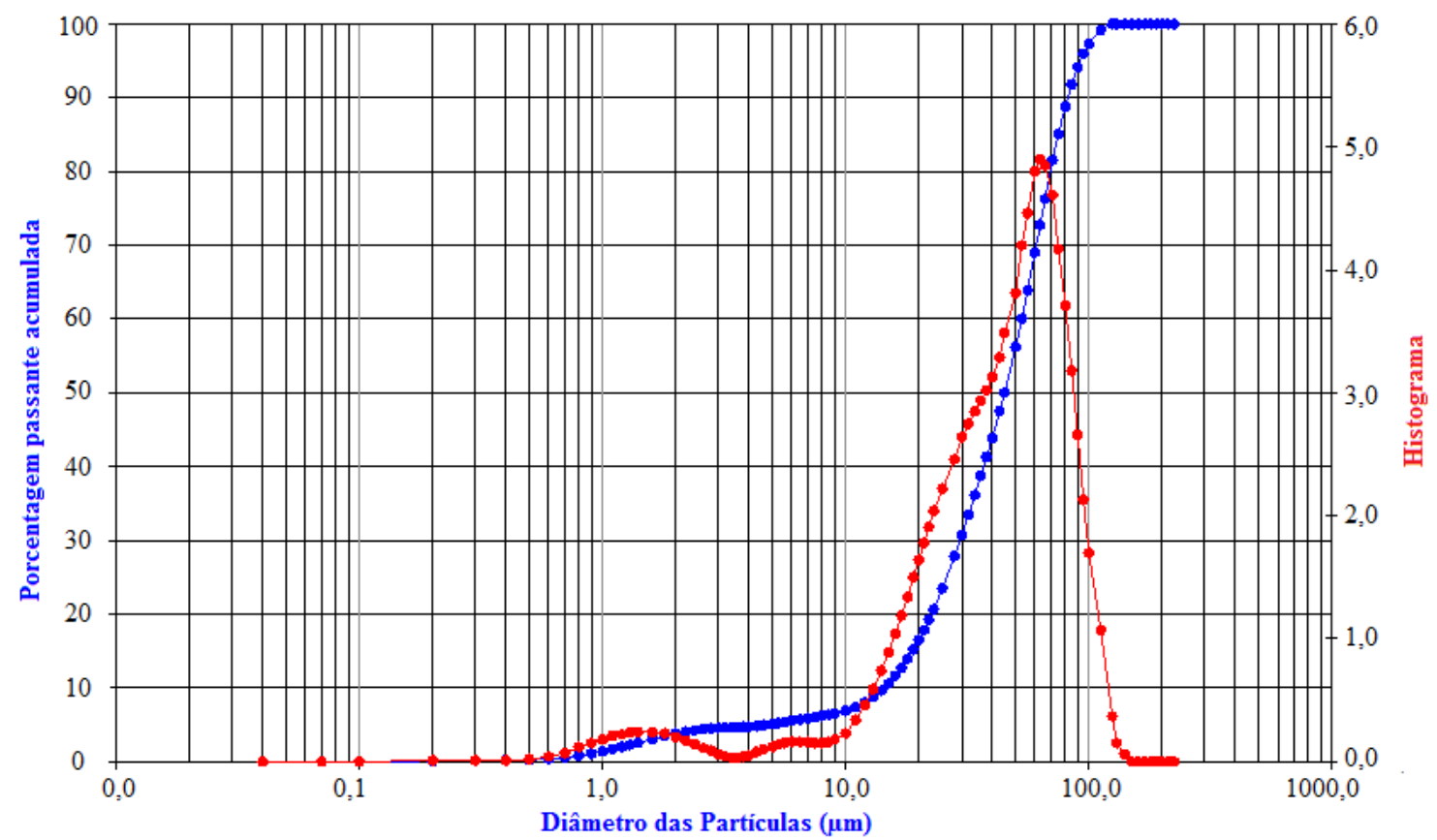

Figura 1. Curva granulométrica do filer

Os agregados utilizados, cujas curvas granulometricas são apresentadas nas figuras 2 e 3 , foram a areia média do Rio São José dos Dourados, de origem granítica, e brita de origem basáltica cuja caracterização encontra-se na tabela 1 .

$\mathrm{O}$ aditivo superplastificante utilizado tem como base uma cadeia de éter carboxílico modificado e foi desenvolvido para o concreto em geral, especialmente para indústria de pré-moldados e concretos protendidos, onde se requer maior durabilidade e desempenho, sendo também indicado para produção de C.A.A. Ele é isento de cloretos e atende às prescrições da norma ASTM C 494 (tipos A e F), ASTM C 107.

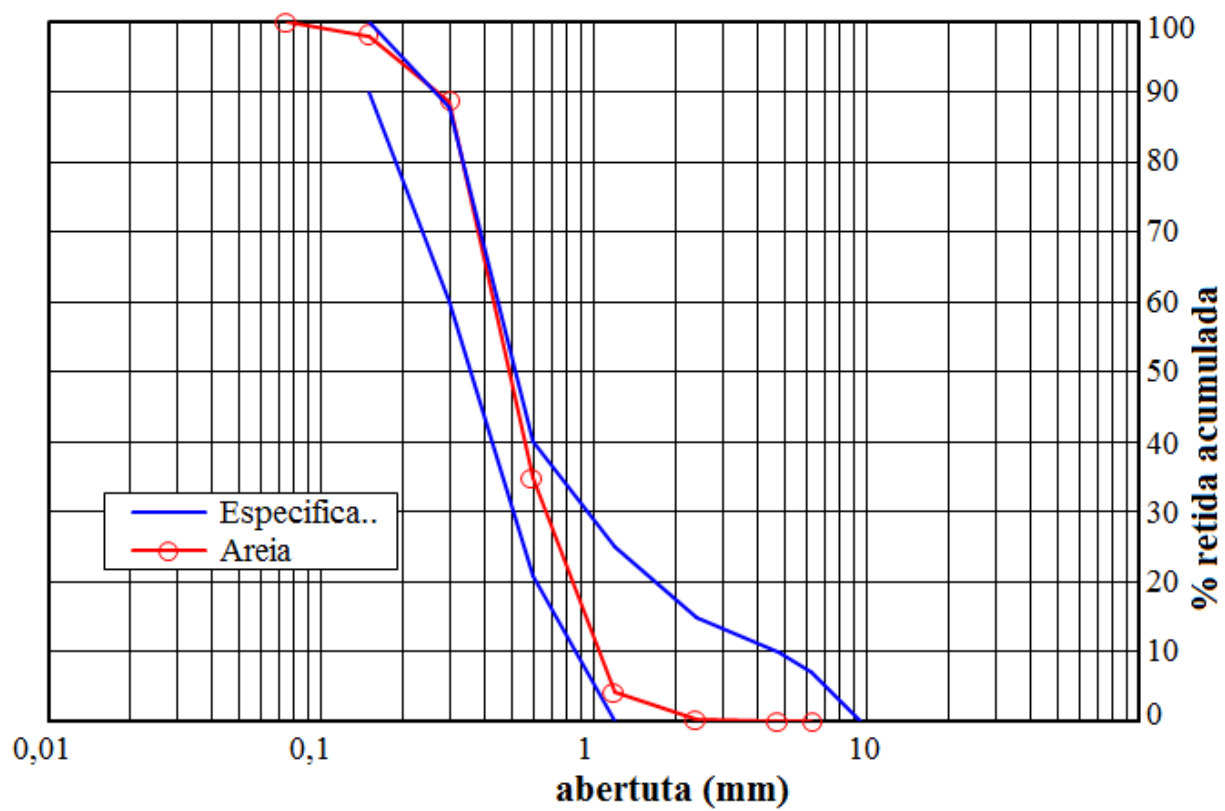

Figura 2. Curva granulométrica do agregado miúdo 
Revista ALCONPAT, Volumen 1, Número 3, Septiembre-Diciembre 2011, Páginas 233 - 249

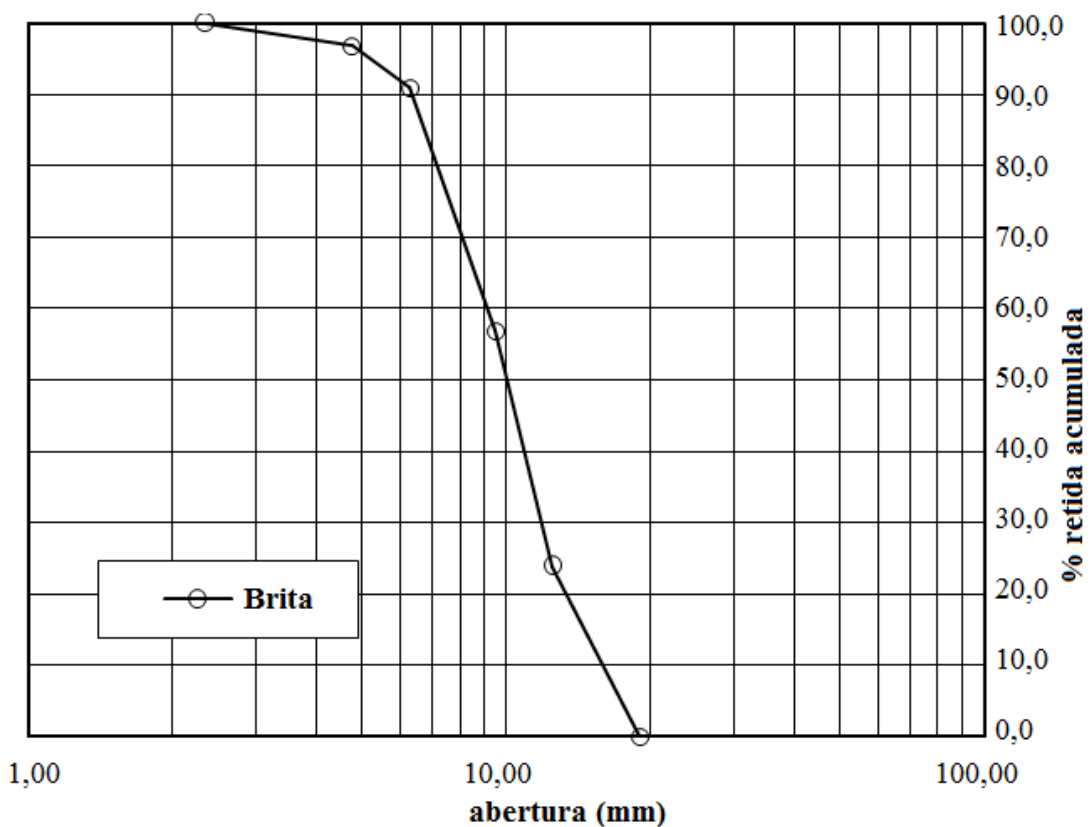

Figura 3. Curva granulométrica do agregado graúdo

Tabela 1. Caracterização dos agregados

\begin{tabular}{|c|c|c|c|c|}
\hline & & & Brita 1 & Areia \\
\hline & & 38,1 & $\overline{0}$ & 0 \\
\hline & & 32,0 & 0 & 0 \\
\hline & & 25,4 & 0 & 0 \\
\hline & & 19,0 & 0 & 0 \\
\hline శ్ర & & 12,7 & 23,8 & 0 \\
\hline $\bar{\Xi}$ & & 9,51 & 56,9 & 0 \\
\hline$\overline{\tilde{J}}$ & छ & 6,30 & 91,0 & 0 \\
\hline$\pi$ & $\Xi$ & 4,76 & 96,8 & 0 \\
\hline 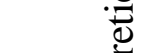 & $\tilde{乛 ే}$ & 2,38 & 100 & 0,4 \\
\hline$a^{\circ}$ & $\bar{\Xi}$ & 1,19 & 100 & 7,6 \\
\hline.$\approx$ & 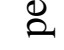 & 0,595 & 100 & 56,9 \\
\hline$\stackrel{\Xi}{0}$ & శ్ & 0,297 & 100 & 94,4 \\
\hline 드 & $\underset{\mathscr{F}}{\exists}$ & 0,149 & 100 & 99,6 \\
\hline 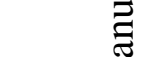 & 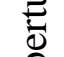 & 0,075 & 100 & 100 \\
\hline ن் & 定 & fundo & 100 & 100 \\
\hline Diâmetr & car & rístico $(\mathrm{mm})$ & 19,0 & 2,38 \\
\hline Módulo & & & 6,54 & 2,59 \\
\hline Massa e & s.s.s & $\mathrm{m} 3)$ & 2,917 & 2,638 \\
\hline Massa e & seca & m3) & 2,881 & 2,650 \\
\hline Massa e & apar & $(\mathrm{g} / \mathrm{cm} 3)$ & 2,987 & 2,631 \\
\hline Massa u & lta ( & & 1,569 & 1,414 \\
\hline Absorçã & $(\%$ & & 1,23 & 0,28 \\
\hline Material & ento & & 0,54 & 0,15 \\
\hline
\end{tabular}


Revista ALCONPAT, Volumen 1, Número 3, Septiembre-Diciembre 2011, Páginas 233 - 249

Com relação às propriedades do concreto no estado fresco, a capacidade do aditivo de redução de água (40\% aproximadamente) melhora as propriedades mecânicas do compósito, mantendo a trabalhabilidade, sem segregação e exsudação. A dosagem recomendada é de 0,5 a 1,0 litros, para cada $100 \mathrm{~kg}$ de material cimentício.

Tabela 2. Propriedades físicas e químicas do cimento utilizado

\begin{tabular}{|l|c|lr|}
\hline Propriedades Químicas & Propriedades físicas & \\
\hline Perda ao fogo (\%) & 3,24 & Finura peneira 200 (\%retida) & 0,32 \\
Insolúveis (\%) & 0,26 & Finura peneira 325 (\%retida) & 1,32 \\
$\mathrm{SiO}_{2}(\%)$ & 19,10 & Blaine $\left(\mathrm{cm}^{2}\right)$ & 4072 \\
$\mathrm{Fe}_{2} \mathrm{O}_{3}(\%)$ & 3,00 & Massa específica aparente $\left(\mathrm{g} / \mathrm{cm}^{3}\right)$ & 0,94 \\
$\mathrm{Al}_{2} \mathrm{O}_{3}(\%)$ & 6,24 & Massa específica absoluta $\left(\mathrm{g} / \mathrm{cm}^{3}\right)$ & 3,12 \\
$\mathrm{CaO}(\%)$ & 64,94 & Início de pega (mim) & 132 \\
$\mathrm{MgO}(\%)$ & 0,76 & Finura peneira 200 (\%retida) & 0,32 \\
$\mathrm{SO}_{3}(\%)$ & 2,74 & Finura peneira 325 (\%retida) & 1,32 \\
$\mathrm{Na}_{2} \mathrm{O}(\%)$ & 0,11 & & \\
$\mathrm{~K}_{2} \mathrm{O}(\%)$ & 0,77 & & \\
Equiv. Alcalino Na & \\
$\mathrm{Cal}$ livre em $\mathrm{CaO}(\%)$ & 0,62 & & \\
\hline
\end{tabular}

2.2 Materiais e Programa Experimental

2.2.1 Concreto - Relação água/Cimento.

As relações água/cimento foram obtidas de acordo com as resistências à compressão pretendidas de $35 \mathrm{MPa}$ e $55 \mathrm{MPa}$. Utilizou-se a expressão dada pela a equação 1 , em função da resistência à compressão aos 28 dias, referentes ao Cimento Portland Brasileiro de alta resistencia (Melo, 2005), equivalente ao Cimento Portland classe III (ASTM C150).

$$
a / c=1,03 \cdot \log \left(\frac{147,32}{f_{c 28}}\right)
$$

A dosagem do concreto resultou nos traços apresentados na Tabela 3, que emprega uma relação água/cimento de 0,64 para obter um concreto classe B 35/45 (resistência à compressão expressa em $\mathrm{MPa}$ ), e uma relação a/c de 0,45 para o concreto de $55 \mathrm{MPa}$, agora denominados $\mathrm{A}$ e $\mathrm{B}$, respectivamente.

Tabela 3. Composição e denominação dos traços de C.A.A.

\begin{tabular}{|c|c|c|c|c|c|c|c|c|}
\hline $\begin{array}{c}\text { Relação } \\
\text { água/cimento }\end{array}$ & $\begin{array}{c}\text { Volume } \\
\text { de } \\
\text { concreto } \\
\text { (L) }\end{array}$ & $\begin{array}{c}\text { Massa } \\
\text { de } \\
\text { cimento } \\
(\mathrm{Kg})\end{array}$ & $\begin{array}{c}\text { Massa } \\
\text { de } \\
\text { Filer } \\
(\mathrm{Kg}) \\
\end{array}$ & $\begin{array}{c}\text { Massa } \\
\text { de } \\
\text { Areia } \\
(\mathbf{K g}) \\
\end{array}$ & $\begin{array}{c}\text { Massa } \\
\text { de } \\
\text { Brita } \\
(\mathrm{Kg}) \\
\end{array}$ & $\begin{array}{c}\text { Massa } \\
\text { de } \\
\text { Água } \\
\text { (Kg) } \\
\end{array}$ & $\begin{array}{c}\text { Teor } \\
\text { de } \\
\text { aditivo } \\
\text { (L) } \\
\end{array}$ & $\begin{array}{r}\text { Designação } \\
\text { do concreto }\end{array}$ \\
\hline 0,45 & 1000 & 459,07 & 175,05 & 781,37 & 845,93 & 213,59 & 3,00 & Concreto B \\
\hline 0,64 & 1000 & 347,20 & 211,82 & 827,36 & 816,76 & 229,16 & 2,10 & Concreto A \\
\hline
\end{tabular}




\subsubsection{Produção do Concreto.}

A produção do concreto obedeceu as seguintes etapas: determinação do teor de agregado graúdo; ajuste da porcentagem de aditivo; e avaliação do concreto de acordo com as propriedades requeridas. Numa primeira fase foram produzidos 20 litros de concreto para o ajuste do teor de brita e de aditivo, e em seguida, foram produzidos 80 litros de concreto para a elaboraçao dos corpos de prova para os ensaios de fluência, retração, resistência à compressão, resistência à tração, e Módulo de elasticidade.

O tempo de mistura para preparo dos compósitos foi realizado em 16 minutos: Agregado graúdo e $80 \%$ da água (1minuto); Cimento, fíler e 15\% da água, (1 minuto e 30 segundos); Areia e pó de pedra (1minuto e 30 segundos); Remoção do material aderido às pás e paredes da betoneira, que permanecia desligada (3 minutos); Betoneira acionada (2 minutos); incorporação da primeira parcela do aditivo e restante da água, (3 minutos); Segunda parcela do aditivo (4 minutos).

\subsubsection{Ensaios de Retração por Secagem}

Os ensaios de retração por secagem foram realizados de acordo com a norma MERCOSUL NM 131:97, a qual define a retração hidráulica como sendo "a redução de volume observada quando o concreto é submetido a uma perda de umidade e mantido à temperatura constante, sem nenhuma espécie de carregamento".

Para cada uma das composições de concreto foram moldados dois corpos-de-prova prismáticos de 150x150x600 mm, os quais foram desmoldados e colocados em recipientes com água saturada de cal, à temperatura de $23,0 \pm 2,0^{\circ} \mathrm{C}$, por 30 minutos, antes de se proceder à leitura do comprimento inicial. Realizada esta leitura, os mesmos, foram novamente estocados em recipientes com água, até a idade de 28 dias. Ao fim do período de cura (28 dias), foi tomada a segunda leitura de comprimento. A seguir, os corpos de prova foram transferidos e estocados em sala climatizada $\left(23,0 \pm 2,0^{\circ}\right)$ e com umidade relativa igual a $50 \pm 4 \%$. As medidas das deformações foram realizadas com o auxílio de extensômetros tipo Carlson, embutidos no concreto. Foram realizadas leituras diárias até a estabilização das deformações, sendo primordial, o uso cuidadoso dos instrumentos medidores e calibradores, sob as mesmas condições de temperatura. As figuras de 4 e 5 ilustram as etapas da moldagem dos corpos-de-prova para ensaio de retração.
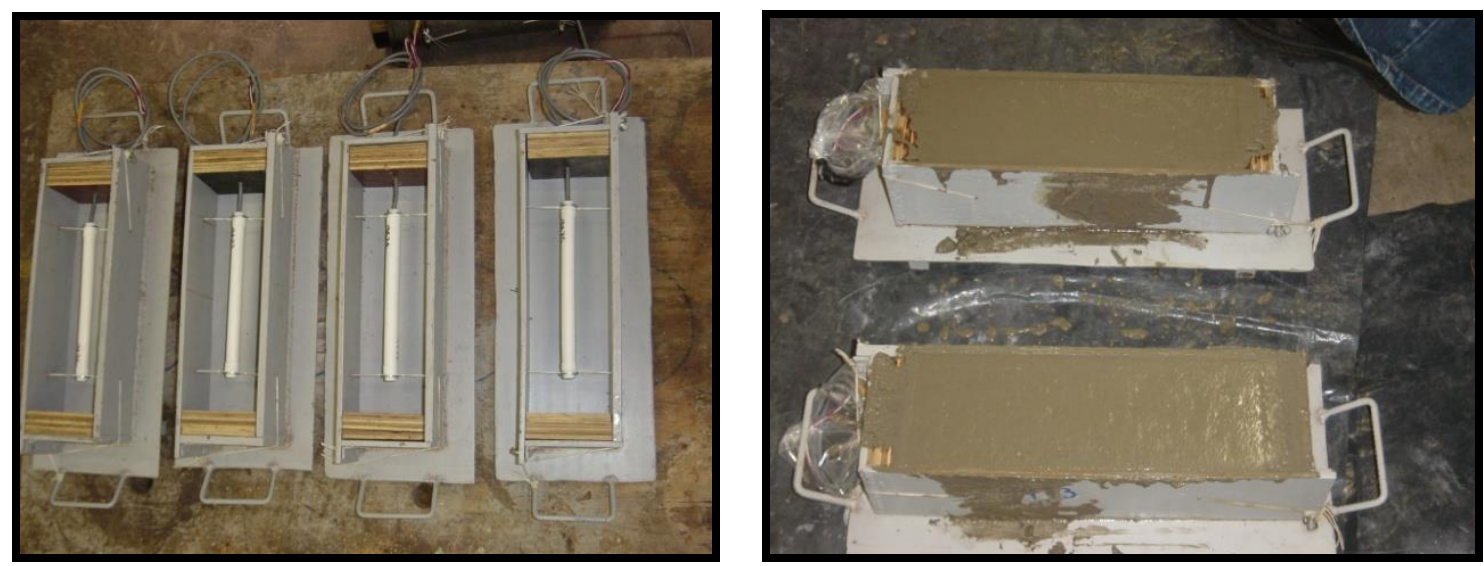

Figuras 4 e 5. Detalhes de extensômetria e da concretagem dos corpos de prova para ensaio de retração. 


\subsubsection{Ensaios para Determinação da Fluência}

Nos ensaios de fluência básica, realizados de acordo com a norma NBR 8224 /83 - Determinação da Fluência (ABNT, 1983), os corpos de prova foram selados conforme ilustram as figuras 6 e 7. Das prescrições desta norma pode-se destacar a necessidade de realização de ensaios complementares de resistência à compressão e de módulo de elasticidade. Os corpos-de-prova cilíndricos, com relação altura/diâmetro > 2 são instrumentados com extensômetros embutidos nos mesmos, para medida das deformações. A tensão de carregamento é igual a $40 \pm 2 \%$ da resistência à compressão do concreto na idade de carregamento. Para a determinação da deformação por retração autógena, utilizam-se dois corpos de prova, munidos de dispositivos de medição da deformação que permanecem descarregados durante todo período de ensaio. A deformação por fluência básica em qualquer idade foi calculada segundo a equação 2:

$$
\varepsilon_{\mathrm{cc}}=\varepsilon_{\mathrm{t}}-\varepsilon_{\mathrm{i}}-\varepsilon_{\mathrm{s}}
$$

Onde:

$\varepsilon_{\mathrm{cc}}$ - deformação por fluência básica; $\varepsilon_{\mathrm{t}}$ - deformação total a partir da leitura de referência nos corpos-de-prova sob carregamento, na idade considerada; $\varepsilon_{i}$ - deformação imediata medida no ato da aplicação da carga; $\varepsilon_{\mathrm{s}}$ - deformação média dos corpos-de-prova complementares não submetidos a carregamento (retração autógena).

Para medida das deformações e da temperatura no interior dos corpos-de-prova de concreto foram utilizados extensômetros tipo Carlson, modelo M4. Os moldes cilíndricos foram envolvidos por borracha cuidadosamente colocada para isolamento total do corpo-de-prova. Com auxílio de barbantes, os extensômetros foram posicionados no interior do corpo-de-prova. Os fios dos extensômetros saem do corpo-de-prova pelo orifício inferior e são devidamente isolados do contato com água ou concreto. Durante a concretagem, o concreto é lançado com cuidado para não alterar o posicionamento dos extensômetros. Na Figura 6 pode-se observar o esquema de colocação dos extensômetros no corpo-de-prova, e na Figura 7 os detalhes da concretagem e nivelamento destes enquanto que a Figura 8 ilustra a sala de ensaios de fluência do Laboratório Cesp de Engenharia civil (LCEC).

Os corpos-de-prova são submetidos ao carregamento em sala climatizada, o carregamento é executado por meio de macacos hidráulicos, as leituras de deformação (medida fornecida em valores de resistência elétrica $\Omega$ (ohms), para posterior conversão em medidas de deformação $\left.\left(\varepsilon_{t}\right)\right)$ foram realizadas periodicamente para determinação da curva de deformação sob carga $\mathrm{x}$ idade. A aparelhagem de execução deste ensaio encontra-se melhor detalhada na NBR 8224.
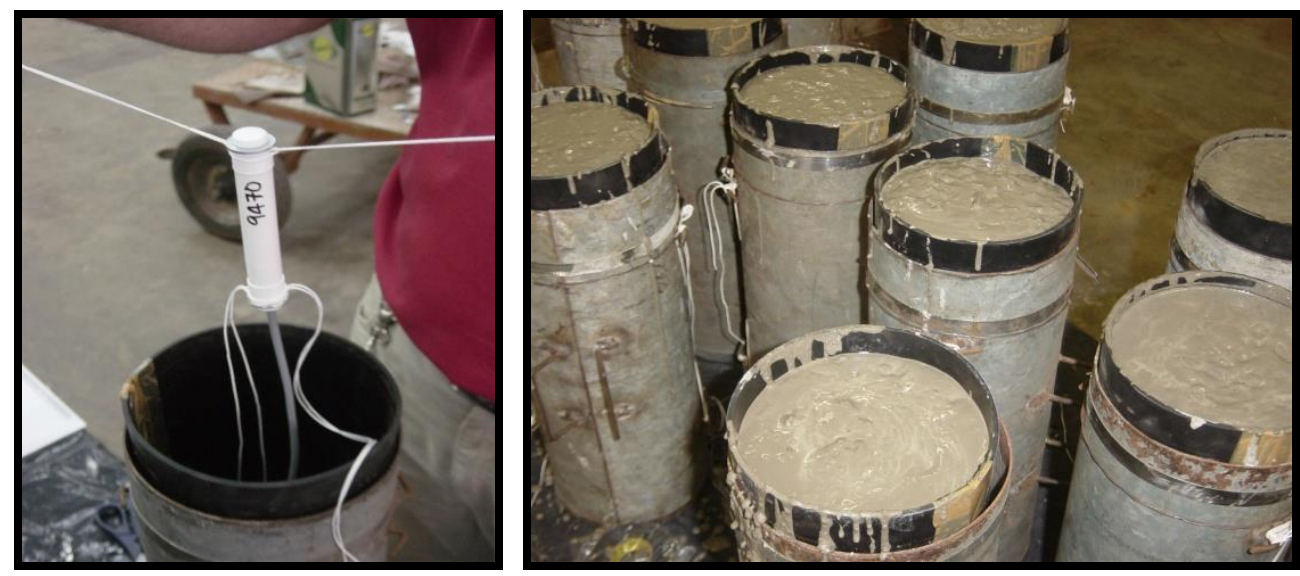

Figuras 6 e 7. Detalhes da Extensômetria e da concretagem e nivelamento dos corpos de prova selados dos ensaios de fluência. 


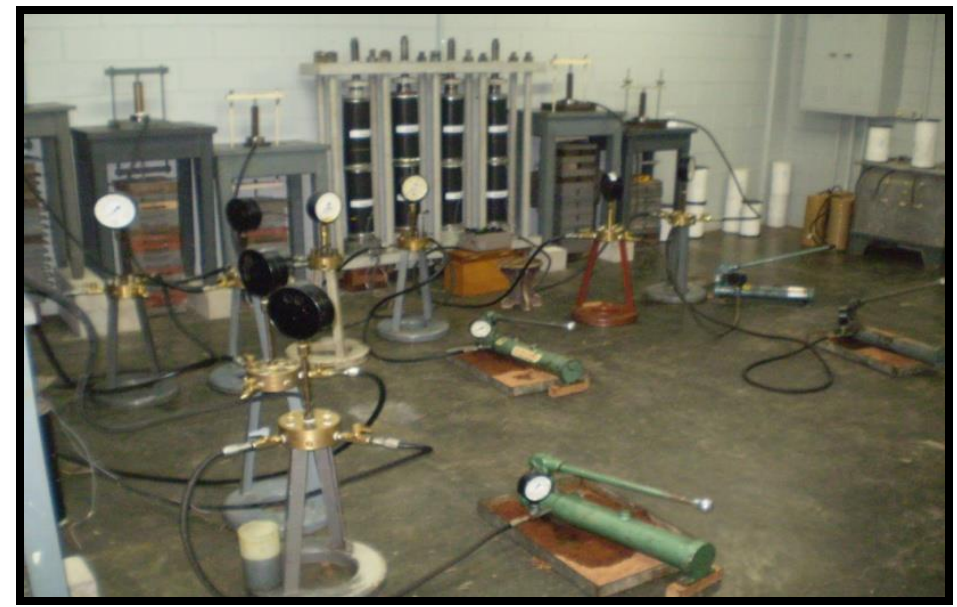

Figura 8. Sala de Fluência do Laboratório CESP de Engenharia Civil(LCEC).

\subsubsection{Métodos para Previsão da Fluência e da Retração por Secagem}

Os métodos para previsão da fluência e da retração, encontrados nas normas nacionais e internacionais de concreto, dão suporte para a rápida estimativa destes valores quando não existem tempo e laboratórios para a realização de ensaios experimentais.

Os coeficientes de fluência foram calculados de acordo com a metodologia proposta pela NBR $6118 / 2003$. Estes coeficientes calculados pela norma foram comparados com os coeficientes de fluência básica experimentais, que são encontrados inserindo os valores dos ensaios na equação 3 abaixo:

$$
\varphi(t)=\frac{\varepsilon_{\text {total }}(\mathrm{t})-\varepsilon_{\mathrm{i}}-\varepsilon_{\mathrm{s}}(\mathrm{t})}{\varepsilon_{\mathrm{i}}}
$$

onde:

$\varepsilon_{\text {total }}(\mathrm{t})=$ deformação total medida nos corpos de prova carregados

$\varepsilon_{\mathrm{i}}(\mathrm{t})=$ deformação inicial medida no momento do carregamento dos corpos de prova $\left(\mathrm{t}=\mathrm{t}_{\mathrm{o}}\right)$ $\varepsilon_{\mathrm{s}}(\mathrm{t})=$ deformação por retração autógena medida em corpos de prova mantidos selados e descarregados

\section{RESULTADOS}

\subsection{Ensaios das Propriedades Mecânicas dos Concretos}

A tabela 4 apresenta os resultados dos ensaios das propriedades mecânicas, referentes aos dois tipos de concreto, A e B, os quais foram realizados nas idades de 3, 7, 14, 28, 90, e 180 dias. 
Revista ALCONPAT, Volumen 1, Número 3, Septiembre-Diciembre 2011, Páginas 233 - 249

Tabla 4. Resultados das propriedades mecânicas dos concretos A e B

\begin{tabular}{|c|c|c|c|c|c|c|}
\hline \multirow{2}{*}{ Ensaio } & \multicolumn{2}{|c|}{$\begin{array}{c}\text { Resistência à } \\
\text { compressão (MPa) }\end{array}$} & \multicolumn{2}{c|}{$\begin{array}{c}\text { Resistência à tração } \\
\text { (MPa) }\end{array}$} & \multicolumn{2}{c|}{$\begin{array}{c}\text { Modulo de } \\
\text { Elasticidade (GPa) }\end{array}$} \\
\hline Traço & Concreto & Concreto & Concreto & Concreto & Concreto & Concreto \\
Idade & A & B & A & B & A & B \\
\hline 3 dias & 23 & 38,1 & 2,4 & 4 & $*$ & $*$ \\
7 dias & 27 & 43,8 & 2,6 & 4,3 & $*$ & $*$ \\
14 dias & 30,5 & 48,8 & 3 & 5,2 & 23,8 & 33,3 \\
28 dias & 33,3 & 52,1 & 3,3 & 5,4 & 29,4 & 35,8 \\
90 dias & 35,2 & 58,3 & 3,5 & 5,7 & $*$ & $*$ \\
180 & 37,4 & 59,2 & 3,6 & 5,7 & 30,2 & 38,5 \\
dias & & & & & & \\
\hline
\end{tabular}

*Observação: ensaios não realizados nesta idade

Os resultados de resistência à compressão aos 28 dias ficaram próximos a $35 \mathrm{MPa}$ e a $55 \mathrm{MPa}$ para os concretos tipo A e B,respectivamente. Os resultados de resistência à tração apresentaram valores compatíveis, em torno de $10 \%$ dos valores encontrados para resistência à compressão. Os valores de módulo de elasticidade apresentaram pouca variação dos 28 dias até os 180 dias, o que também ocorreu com os resultados de resistência, o que demonstra certa estabilização mecânica depois dos 28 dias.

\subsection{Ensaios de Retração por secagem}

A figura 9 apresenta os resultados de retração (através do grafico deformaçao x idade) realizados para os concretos A e B, respectivamente. Foram monitorados, para cada tipo de concreto, dois corpos-de-prova, sendo as respectivas curvas a média dos valores dos dois corpos de prova de cada tipo de concreto.

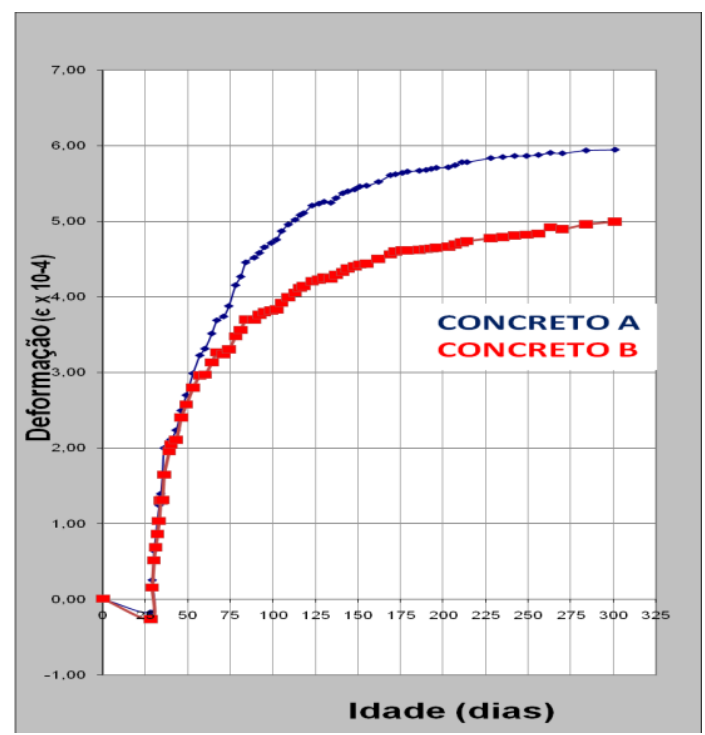

Figura 9. Comparação da Retração entre os A e B.

A variação negativa da deformação por retração, observada no início dos ensaios (período de 0 a 28 dias) deve-se à imersão dos corpos-de-prova em água, segundo especifica a norma MERCOSUL NM 131:97. O concreto que apresentou menor resistência à compressão e menor módulo de elasticidade (Concreto A ) foi aquele que apresentou resultados levemente superiores. 
Revista ALCONPAT, Volumen 1, Número 3, Septiembre-Diciembre 2011, Páginas 233 - 249

Mehta e Monteiro (1994) relatam que concretos com maiores teores de argamassa geralmente apresentam maiores taxas de deformação, o concreto B possui $70 \%$ de argamassa, enquanto o concreto A possui $72 \%$ de argamassa, provavelmente a diferença no teor de argamassa proporcionou uma maior deformação por retração no concreto A.

Os concretos auto-adensáveis apresentaram retração ligeiramente superior, aos resultados de concretos convencionais, com resistência mecânica similar, encontrados na literatura (Silva, 2007), ressaltando a influência dos materiais utilizados nos diferentes estudos; O elevado teor de argamassa do C.A.A. (maior ou igual a 70\%) resulta em maiores valores de deformação por retração.

3.3 Ensaios de fluência

As figuras 10(a) e 10(b) apresentam os resultados dos corpos-de-prova que não foram submetidos a carregamento.
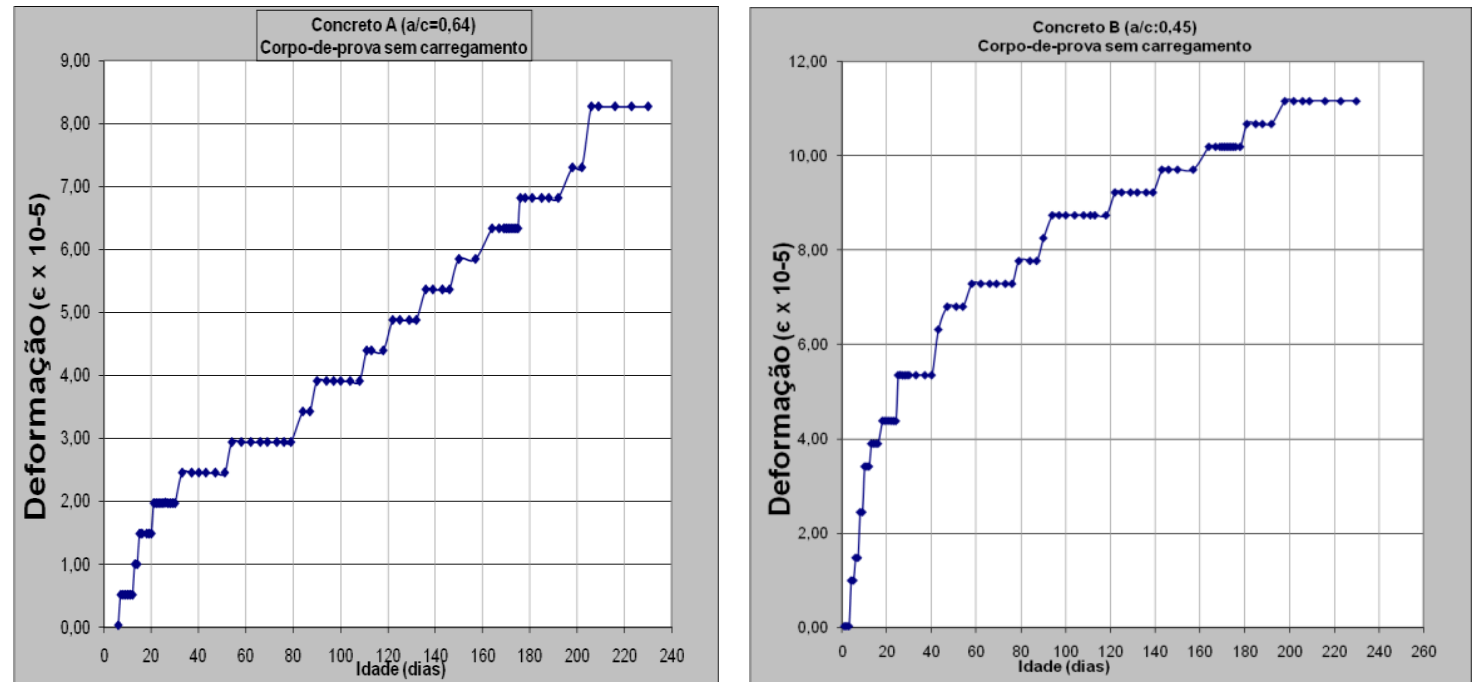

Figura 10. Deformação do corpo de prova não carregado (deformação por retração autógena) (a) Concreto A; (b) Concreto B

A figura 10 mostra que, quando se analisam elementos isolados (sem perda de água para o meio ambiente) e sem carregamento (onde os parâmetros mecânicos dos compósitos perdem importância), os traços com maior quantidade de cimento (Concreto B) demandam maior quantidade de água, ocasionada, provavelmente, pela maior velocidade de formação dos compostos hidratados de cimento (silicato de cálcio hidratado e aluminatos de cálcio hidratado), ocasionando assim maiores deformações (Concreto B), deformação final igual a aproximadamente $11 \times 10-5$, e deformação final igual a aproximadamente $8 \times 10-5$. (concreto A) Nas figuras a seguir (11 a 14 ) são apresentados o comportamento com relação à fluência sob carregamento ao longo do tempo. Cada gráfico corresponde a média de dois corpos-de-prova. Foram ensaiados no total dezesseis corpos-de-prova, o que totalizou oito corpos de prova por composição por idade do concreto $(7,14,28$, e 56 dias $)$. 
Revista ALCONPAT, Volumen 1, Número 3, Septiembre-Diciembre 2011, Páginas 233 - 249
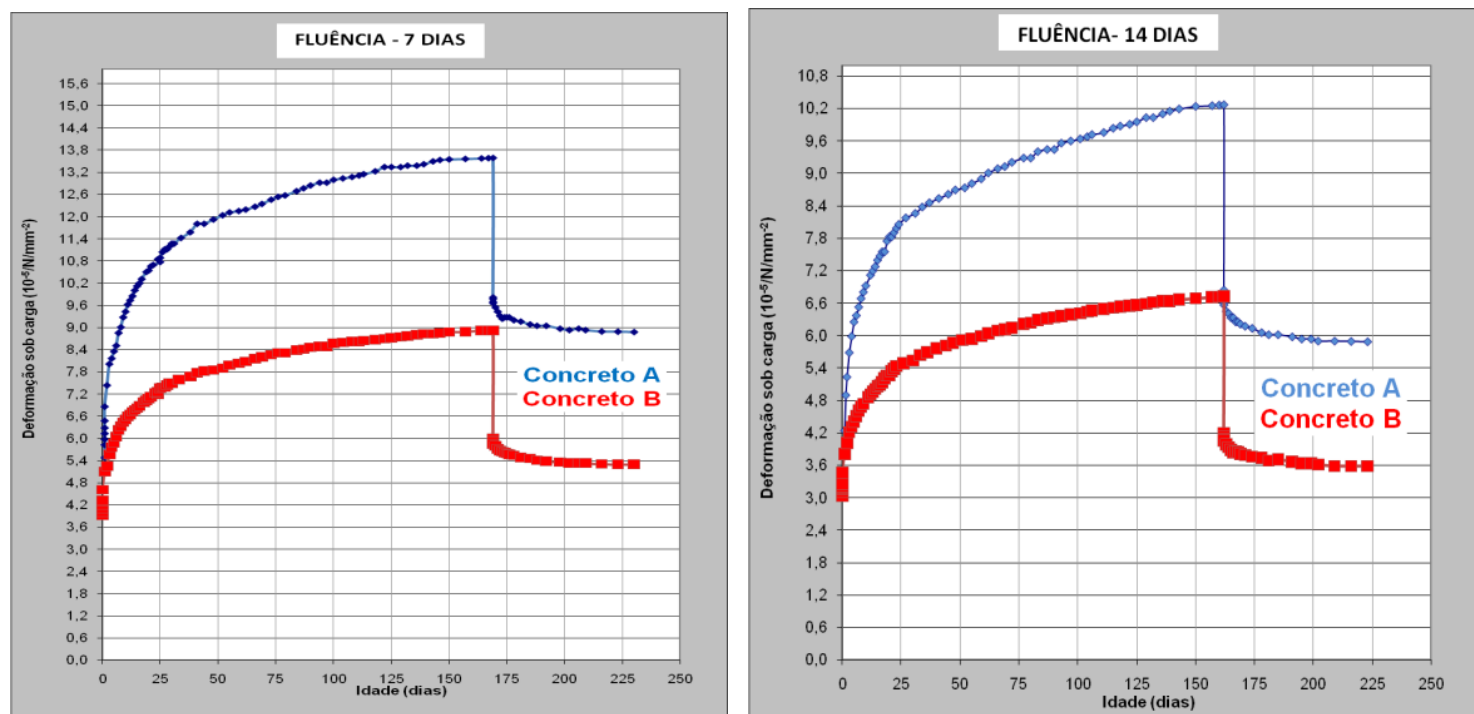

Figuras 11 e 12- Comparação da fluência básica dos concretos A e B carregados aos 7 dias, e 14 dias, respectivamente.

As figuras 11 e 12 retratam que o carregamento poderia ter permanecido por mais tempo para melhor estabilização da fluência básica, principalmente aos 14 dias. Por outro lado, as estabilizações das deformações sob carga máximas do concreto $\mathrm{B}$, e as estabilizações das deformações residuais de ambos os concretos mostraram-se adequadas, com a repetição das 3 ultimas leituras. Os corpos-de-prova de maior resistência, e de maior módulo de elasticidade (Concreto B) apresentaram deformações sob carga máximas em torno de $8,8 \times 10^{-5} / \mathrm{N} / \mathrm{mm}^{2}$, no ensaio iniciado aos sete dias, e $6,8 \times 10^{-5} / \mathrm{N} \cdot \mathrm{mm}^{2}$ no ensaio de 14 dias, menores que os valores do concreto A $\left(13,6 \times 10^{-5} / \mathrm{N} / \mathrm{mm}^{2}\right.$, no ensaio iniciado aos sete dias, e $10,4 \times 10^{-5} / \mathrm{N} / \mathrm{mm}^{2}$ no ensaio de 14 dias).
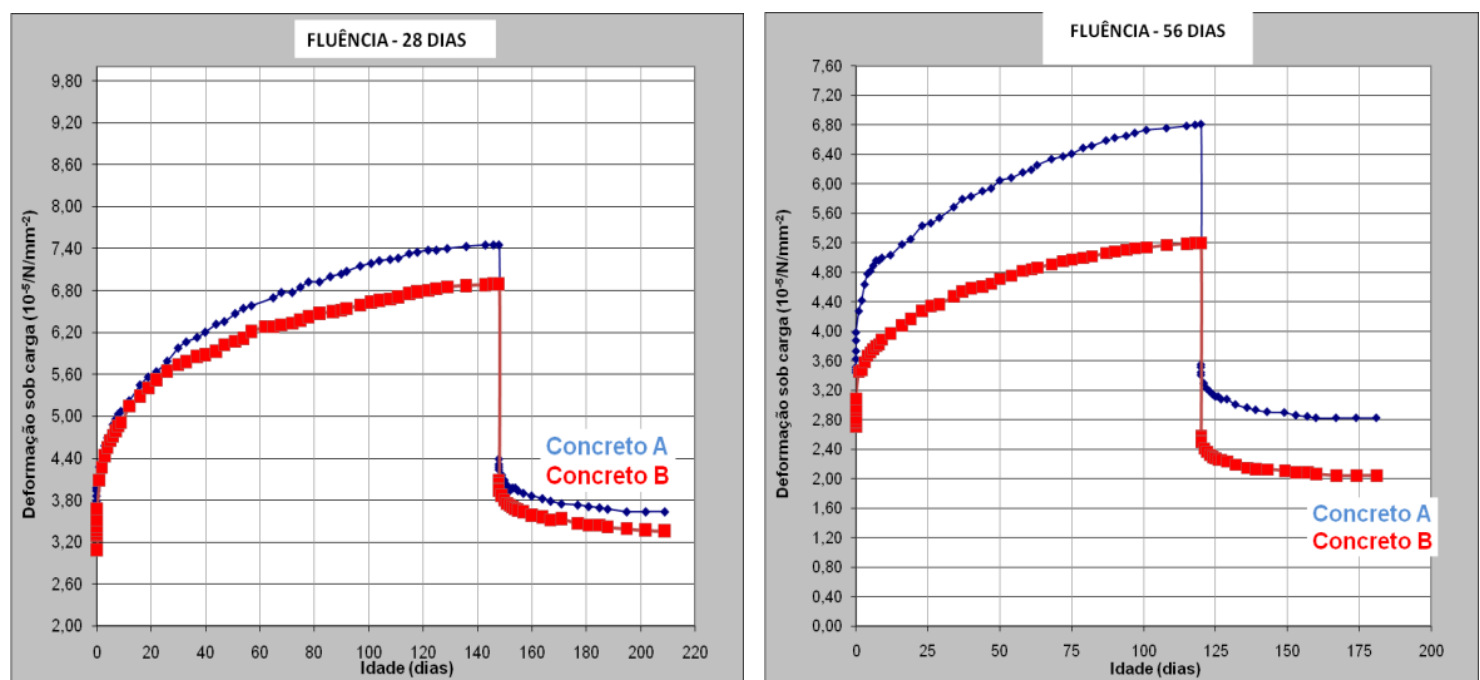

Figuras 13 e 14. Comparação da fluência básica dos concretos A e B carregados aos 28, e 56 dias, respectivamente.

A figura 13 mostra que os ensaios de fluência iniciados aos 28 dias apresentaram estabilizações adequadas (repetição das 3 ultimas leituras) tanto nas máximas deformações sob carga, quanto nas deformações residuais. Observa-se que os corpos-de-prova de menor relação água/cimento (Concreto B), apresentaram valores menores para as deformações sob cargas máximas, em torno 
Revista ALCONPAT, Volumen 1, Número 3, Septiembre-Diciembre 2011, Páginas 233 - 249

de $6,8 \times 10^{-5} / \mathrm{N} / \mathrm{mm}^{2}$, que o concreto A, cujos valores de deformação sob carga são da ordem de $7,5 \times 10^{-5} / \mathrm{N} / \mathrm{mm}^{2}$. Esta diferença entretanto, foi menor quando comparada com a apresentada nas idades de 7 e 14 dias.

A figura 14 apresenta os resultados experimentais dos ensaios de fluencia básica iniciados aos 56 dias. Pode-se observar que houve uma estabilizaçao adequada tanto nas máximas deformações sob carga, quanto nas deformações residuais, com o concreto A necessitando de mais tempo para se estabilizar, tempo este superior a 100 dias de ensaio. Os corpos-de-prova do concreto B novamente apresentaram valores de deformação máxima sob carga inferiores aos do concreto A, ou seja de $5,2 \times 10^{-5} / \mathrm{N} / \mathrm{mm}^{2}$ contra $6,8 \times 10^{-5} / \mathrm{N} / \mathrm{mm}^{2}$. Observou-se também que o tempo de inicio do carregamento leva a valores menores de deformações sob carga finais e residuais, devido ao incremento das propriedades mecânicas com o tempo.

\subsubsection{Parâmetros de fluência}

A Tabela 5 apresenta os parâmetros de fluência obtidos nos ensaios experimentais realizados aos $7,14,28$, e 56 dias nos concretos A e B.

Tabela 5. Parâmetros de fluência

\begin{tabular}{|l|c|c|c|c|c|}
\hline Traço (a/c) & Idade (dias) & $\left(\mathbf{G}_{\mathbf{i}}\right)$ & $\left(\mathbf{c t}_{\mathbf{t}}\right)$ & $\left(\mathbf{\epsilon}_{\mathbf{s}}\right)$ & $(\mathbf{\epsilon c c})$ \\
\hline Concreto A & 7 dias & 0,0007 & 0,0017 & 0,00008 & 0,00092 \\
Concreto B & 7 dias & 0,00075 & 0,0016 & 0,00011 & 0,00074 \\
Concreto A & 14 dias & 0,00057 & 0,00127 & 0,00008 & 0,00062 \\
Concreto B & 14 dias & 0,00063 & 0,00132 & 0,00011 & 0,00058 \\
Concreto A & 28 dias & 0,00048 & 0,000932 & 0,0008 & 0,000372 \\
Concreto B & 28 dias & 0,00069 & 0,001358 & 0,00011 & 0,000558 \\
Concreto A & 56 dias & 0,00048 & 0,000917 & 0,00008 & 0,000357 \\
Concreto B & 56 dias & 0,00061 & 0,00114 & 0,00011 & 0,00042 \\
\hline
\end{tabular}

3.4 Comparação entre os coeficientes experimentais e os coeficientes fornecidos pelas normas De acordo com a NBR 6118 o cálculo dos coeficientes de fluência depende de vários fatores, tais como umidade, temperatura, área do elemento estrutural, espessura, idade, entre outros. Com base nas diversas informações da estrutura foram calculados alguns coeficientes preliminares ( $\phi$, $\phi f, \phi d, \phi 1 c, \phi 2 c)$ para que se possa estimar o coeficiente de fluência $(\psi)$. Estes coeficientes dependem de alguns fatores conforme apresentado a seguir:

- Фa ou coeficiente de fluência rápida: varia de acordo com o tipo de cimento, idade fictícia, e temperatura média;

- pf ou coeficiente de fluência irreversível: depende da umidade relativa, espessura fictícia, e consistência do concreto. Observa-se aqui que a norma NBR 6118[7] especifica valores áximos de abatimento de $15 \mathrm{~cm}$, o que não atende o abatimento dos concretos fluidos; $\phi d$ ou coeficiente de fluência reversível: depende apenas do tempo de carregamento; $\phi 1 \mathrm{c}^{1}$ ou

$1,2 * \phi 1$ c e $\phi 2 \mathrm{c}$ entram no cálculo da determinações de $\phi f$ 
Revista ALCONPAT, Volumen 1, Número 3, Septiembre-Diciembre 2011, Páginas 233 - 249

coeficiente que depende da umidade relativa e da consistência do concreto; $\$ 2 \mathrm{c}^{2}$ ou coeficiente que depende da espessura fictícia da peça.

O coeficiente de fluência $(\varphi)$ é encontrado pela soma de $\phi a$, , $f$, $\phi d$, e a deformação por fluência, válida para $\mathrm{t}_{0}=28$ dias, dada pela equação 4 , ou seja

$$
\varepsilon_{\mathrm{cc}}(\mathrm{t}, \mathrm{to})=\varepsilon_{\mathrm{cca}}+\varepsilon_{\mathrm{ccd}}+\varepsilon_{\mathrm{ccf}}=\frac{\sigma_{\mathrm{c}}}{\mathrm{E}_{\mathrm{c} 28}} \varphi(\mathrm{t}, \mathrm{to})
$$

A Tabela 6 apresenta os valores dos coeficientes ( $\phi$ a, $\phi f, \phi d, \phi 1 c, \phi 2 c$, e $\varphi$ ) calculados de acordo com a NBR 6118 para os concretos A e B, enquanto que na Tabela 7 estão listados os valores dos coeficientes de fluência calculados experimentalmente, usando-se a equação 3 com os resultados dos concretos A e B apresentados na Tabela 5. As figuras 15 e 16 apresentam os gráficos comparando os dois concretos.

Tabela 6. Coeficiente de fluência calculados de acordo com NBR 6118

\begin{tabular}{|l|c|c|c|c|c|c|c|}
\hline Traço (a/c) & $\begin{array}{c}\text { Idade } \\
\text { (dias) }\end{array}$ & $\mathbf{\phi a}$ & $\mathbf{\phi f}$ & $\mathbf{\phi d}$ & $\mathbf{\phi 1 c}$ & $\mathbf{\phi 2 c}$ & $\begin{array}{c}\text { Coeficiente } \\
\text { de fluência } \\
(\boldsymbol{\varphi})\end{array}$ \\
\hline Concreto A & 7 & 0,2806 & 0,8957 & 0,3681 & 1,6 & 1,217817 & 1,5444 \\
Concreto B & 7 & 0,2806 & 0,8957 & 0,3681 & 1,6 & 1,217817 & 1,5444 \\
Concreto A & 14 & 0,1995 & 0,6820 & 0,36692 & 1,6 & 1,217817 & 1,24842 \\
Concreto B & 14 & 0,1995 & 0,6820 & 0,36692 & 1,6 & 1,217817 & 1,24842 \\
Concreto A & 28 & 0,1312 & 0,468658 & 0,364183 & 1,6 & 1,217817 & 0,964041 \\
Concreto B & 28 & 0,1312 & 0,468658 & 0,364183 & 1,6 & 1,217817 & 0,964041 \\
\hline
\end{tabular}

Tabla 7. Valores dos Coeficientes de fluência calculados por meio dos resultados experimentalmente

\begin{tabular}{|l|c|c|c|c|c|c|}
\hline Traço (a/c) & Idade (dias) & $\boldsymbol{\varepsilon}_{\mathbf{i}}$ & $\boldsymbol{\varepsilon}_{\mathbf{t}}$ & $\boldsymbol{\varepsilon}_{\mathbf{s}}$ & $\boldsymbol{\varepsilon} \mathbf{c c}$ & $\begin{array}{c}\text { Coeficiente de } \\
\text { fluência ( } \boldsymbol{\Psi})\end{array}$ \\
\hline Concreto A & 7 dias & 0,0007 & 0,0017 & 0,00008 & 0,00092 & 1,3143 \\
Concreto B & 7 dias & 0,00075 & 0,0016 & 0,00011 & 0,00074 & 0,9867 \\
Concreto A & 14 dias & 0,00057 & 0,00127 & 0,00008 & 0,00062 & 1,0877 \\
Concreto B & 14 dias & 0,00063 & 0,00132 & 0,00011 & 0,00058 & 0,9206 \\
Concreto A & 28 dias & 0,00048 & 0,000932 & 0,0008 & 0,000372 & 0,7750 \\
Concreto B & 28 dias & 0,00069 & 0,001358 & 0,00011 & 0,000558 & 0,8087 \\
Concreto A & 56 dias & 0,00048 & 0,000917 & 0,00008 & 0,000357 & 0,7438 \\
Concreto B & 56 dias & 0,00061 & 0,00114 & 0,00011 & 0,000420 & 0,6885 \\
\hline
\end{tabular}

A. L. N. Ferraz, M. P. Barbosa, F. M. Salles, N. O. Pinto Jr. 
Revista ALCONPAT, Volumen 1, Número 3, Septiembre-Diciembre 2011, Páginas 233 - 249

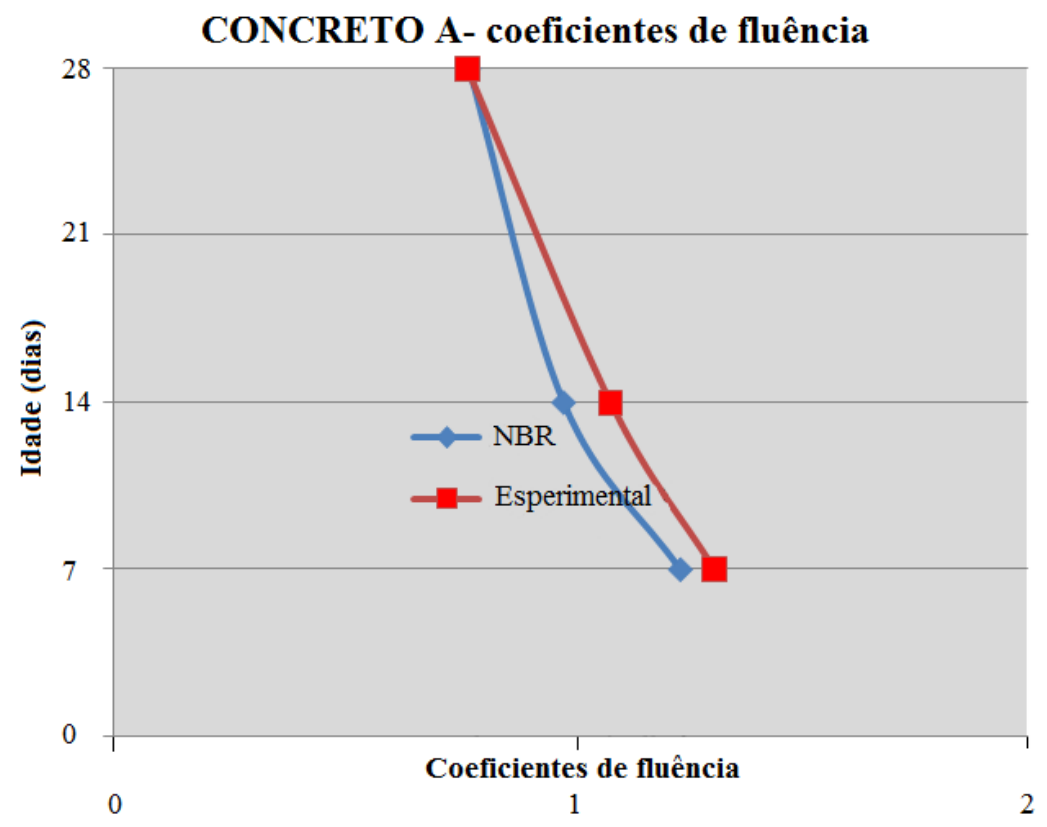

Figura 15. Variação dos coeficientes de fluência (concreto A).

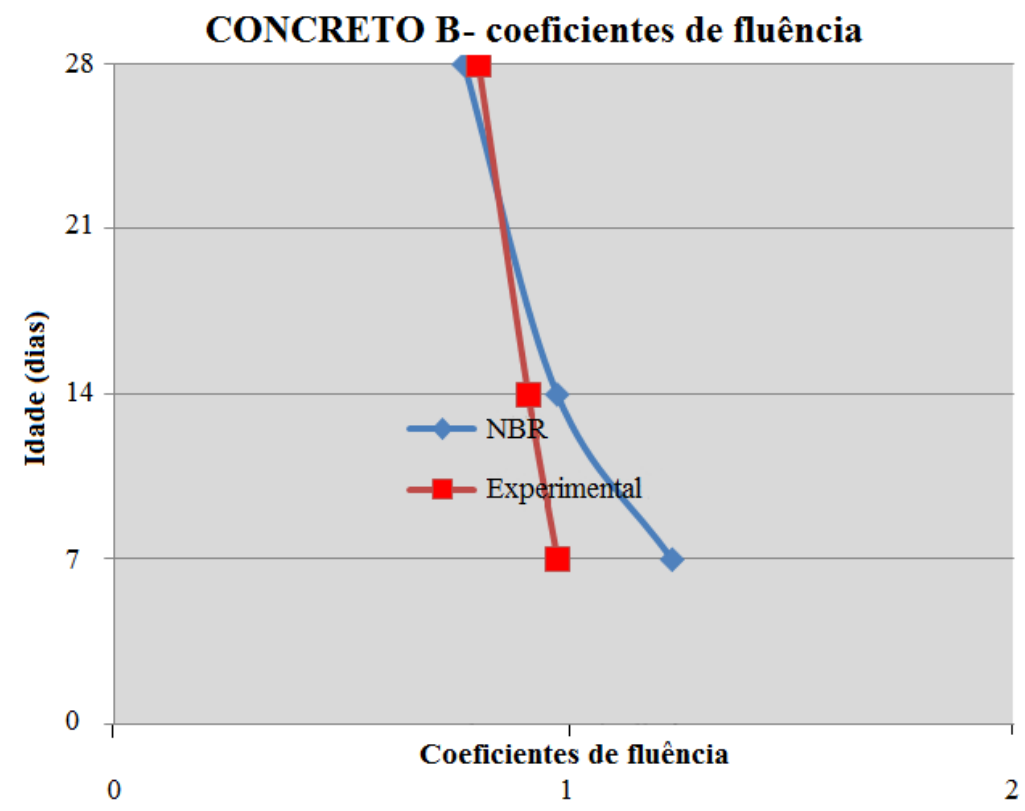

Figura 16. Variação dos coeficientes de fluência (concreto B).

\section{DISCUSSÕES E CONCLUSÕES}

Os ensaios de retração se mostraram adequados, apresentando curvas semelhantes com valores de deformação ligeiramente superiores para o concreto A. A literatura afirma que Concretos com maiores teores de argamassa apresentam maiores taxas de deformação. Neste estudo, o concreto tipo A possui $72 \%$ de argamassa, enquanto o concreto tipo B possui $70 \%$ de argamassa. Provavelmente a diferença no teor de argamassa tenha proporcionado uma maior deformação por retração no concreto tipo A .

Nos ensaios de fluência, os tempos dos ensaios, carregamento, descarregamento, e estabilização das deformações residuais, foram adequados, com as curvas apresentando assíntotas bem 
Revista ALCONPAT, Volumen 1, Número 3, Septiembre-Diciembre 2011, Páginas 233 - 249

definidas. Os corpos-de-prova com idades mais avançadas (28 dias, e 56 dias) apresentaram curvas com melhores padrões de estabilização, repetição das 3 ultimas leituras.

Os resultados dos corpos-de-prova sem carregamento, apresentaram deformações autógenas máximas, aproximadamente 10 vezes menores que os valores das leituras de deformação por retração, e mostram que o traço de concreto com maior quantidade de cimento (concreto A) demanda maior quantidade de água, ocasionada, provavelmente, pela maior velocidade de formação dos compostos hidratados de cimento (silicato de cálcio hidratados e aluminatos de cálcio hidratados), ocasionando assim maiores deformações. Observa-se que o concreto B apresentou deformação final de aproximadamente $11 \times 10^{-5}$ enquanto que o concreto $\mathrm{A}$ apresentou deformação final de aproximadamente $8 \times 10^{-5}$.

Os valores das máximas deformações sob carga foram maiores para os traços de menor módulo de elasticidade, como esperado. Com o aumento do tempo inicial de carregamento dos ensaios os patamares máximos de deformações diminuem, devido à evolução com o tempo das propriedades mecânicas do concreto.

Verifica-se que houve uma boa aproximação entre os coeficientes experimentais e os calculados por Norma; Embora a NBR 6118 leve em consideração valores máximos de abatimento de $15 \mathrm{~cm}$ (portanto não houve diferença nos coeficientes de fluência na mesma idade quando alteramos a relação água/cimento, já que ambos os traços utilizam superplastificante e são fluidos portanto foram enquadrados no valor máximo de abatimento $(15 \mathrm{~cm})$.

Os coeficientes calculados pela NBR 6118 foram maiores em todas as idades, tanto para o concreto A, como para o concreto $\mathrm{B}$, devido, provavelmente, pelos coeficientes experimentais serem calculados para fluência básica, enquanto os calculados pela NBR 6118 consideram a fluência total.

No cálculo da deformação por fluência o coeficiente é multiplicado pela tensão dividida pelo módulo de elasticidade, alterando desta maneira os valores de deformação para concretos de diferentes resistências, e diferentes relações água/cimento.

\section{AGRADECIMENTOS}

Os autores agradecem ao Laboratório CESP de Engenharia Civil -LCEC e a FAPESP pelo financiamento do projeto.

\section{REFERÊNCIAS}

Almeida L. C. (2006), Emprego de Técnicas de Análise Inversa para Identificação de Parâmetros a partir de Dados de Monitoração em Elementos Estruturais, Tese de Doutorado, Universidade Estadual Paulista-Unicamp, 191p. Cam

American Concrete Institute (2005), Building Code Requirements for Structural Concrete \& Commentary. ACI 318-05. Can be ordered at: http://www.aci-int.org/PUBS/newpubs/318-05.htm American Society for Testing and Materials (1992), Specification for Chemical Admixtures for Use in Producing Flowing Concrete, ASTM C 1017. In: Annual Book of ASTM Standards. Philadelphia.

American Society for Testing and Materials (1992), Standard Specification for Chemical Admixtures for Concrete, ASTM C 494 / C494M. In: Annual Book of ASTM Standards. Philadelphia

American Society for Testing and Materials (2007), International made three technical changes to ASTM C 150 - Specification for Portland Cement. 
Revista ALCONPAT, Volumen 1, Número 3, Septiembre-Diciembre 2011, Páginas 233 - 249

Associação Brasileira de Normas Técnicas (1983), Concreto endurecido - determinação da fluência, NBR 8224 /83. Rio de Janeiro, 1983.

Associação Brasileira de Normas Técnicas (2003), Projeto de estruturas de concreto Procedimento, NBR 6118/2003. Rio de Janeiro, 2003.

Comite Euro-International du Beton (1990), CEB-FIP Model code 1990. Lausanne, 1991. (Bulletin d'Information, 203).

Kalintzis C. A. A. (2000), Estudo da Fluência do concreto de elevado desempenho, Dissertação de mestrado Escola Politécnica da Universidade de São Paulo, 123 pp.

Melo K.A. (2005), Contribuição à dosagem de concreto auto-adensável com adição de filer calcário, 180p, Dissertação de mestrado, UFSC, Florianópolis, SC.

Mercosul NM 131:97 (1998), Concreto endurecido - Determinação da retração hidráulica ou higrométrica do concreto, Comité Mercosul de Normalización. 1998.

Neville A. M. (1997), Propriedades do Concreto, Editora Pini, São Paulo, 828 pagina, 2 o edição. Okamura H. (1997), Self-compacting high performance concrete, Concrete International. pp. 5054. v. 19. No. 7.

Persson B. (2005), Self Consolidating Concrete, High Performance and Normal Concrete affected by creep at different age, curing, loading level, strength and water-cement ratio with some interrelated properties, In: IV International ACI/CANMET Conference on Quality of Concrete Structures and Recent Advances in Concrete Material, Olinda. Anais: CD-ROOM.

Seng V., Shima H. (2005), Creep and Shrinkage of self-compacting concrete with different limestone powder contents, SCC-2005, Oct.30-Nov.2, Chicago-USA, 2005.

Silva E.F. (2007), Variações dimensionais em concretos de alto desempenho contendo aditivo redutor de retração, Tese de Doutorado. Universidade Federal do Rio de Janeiro, COPPE/UFRJ. 332p. Rio de Janeiro, 2007.

Su N. et al. (2001), A Simple Mix Design Method for Self-Compacting Concrete. Cement and Concrete Research No. 31, pp.1799-1807. 